\title{
A preliminary study to investigate effectiveness of a mixed extract of Dermatophagoides sp. house dust mites and Alternaria sp. mold
}

\author{
${ }^{1}$ Hospital Universitario de La Plana, Vila-real, Castellón, Spain \\ ${ }^{2}$ Hospital Universitario Doctor Peset, Valencia, Spain \\ ${ }^{3}$ Hospital Clínico Universitario de Valencia, Valencia, Spain
}

\section{KEY WORDS}

Real-world evidence; subcutaneous

immunotherapy; house dust mites;

Dermatophagoides; Alternaria; quality of life.

\author{
Corresponding author \\ David El-Qutob \\ Hospital La Plana de Vila-real \\ Carretera Vila-Real a Burriana km 0,5 s/n \\ 12540 Vila-real \\ Castellón, Spain \\ ORCID ID: 0000-0003-4837-782X \\ E-mail: elqutob@comv.es
}

Doi

10.23822/EurAnnACI.1764-1489.185

\begin{abstract}
Summary
Background and objective. Although the administration of single-allergen extracts is recommended, there are polysensitized patients who require a different strategy. This study evaluates the effectiveness of an extract containing a mixture of house dust mites (HDM) and mold allergens in polysensitized patients with asthma andlor rhinitis. Methods. Using validated questionnaires, we assessed asthma and rhinitis control and quality of life (QOL) of patients that received a combined immunotherapy of HDM and mold in routine clinical practice. Results. 39 polysensitized patients with asthma andlor rhinitis were included. After 6 months of follow up, asthma control increased significantly from baseline and was maintained at 12 months. However, QOL of asthma patients did not change significantly from baseline to month 6 or 12, but at month 12,57.9\% of them improved their score and $5.3 \%$ maintained the same. On the other hand, QOL of $76.9 \%$ patients with rhinitis improved significantly at both 6 and 12 months. Conclusions. In this preliminary study, the administration of immunotherapy based on the combination of allergens from HDM and mold, besides being effective, also allows an increase in the quality of life of patients with asthma andlor rhinitis.
\end{abstract}

\section{Impact statement \\ A mixed extract with house dust mites and molds shows effectiveness and improves quality of life of patients.}

\section{Introduction}

Allergen immunotherapy (AIT) is the only procedure currently available that can modify respiratory allergy. Its objective is to reduce allergic symptoms and drug intake $(1,2)$. This type of treatment can be administered subcutaneously through injections over a period of years, or sublingually through the daily or almost daily administration of allergen extracts.

The European Medicines Agency (EMA) recommends the development and administration of AIT using a single allergen or mixtures with as few allergens as possible, trying to avoid mixtures of seasonal and perennial allergens or allergens with proteolytic activity (3). However, many patients with respirato- ry allergy are sensitized to multiple allergens. Although AIT has been shown to be effective in polysensitized patients, its management has not yet been standardized (4). The main criteria in these patients are based on identifying the most clinically relevant allergens and administering immunotherapy with the allergen causing the most intense and bothersome symptoms. Another alternative is to administer two vaccines consecutively when two of the major allergens cause a significant deterioration in the patient's quality of life (4).

A survey of current clinical practice found that $58 \%$ of polysensitized patients were treated with AIT based on a single allergen extract, while the remaining $42 \%$ were treated with AIT based 
on a combination of allergens, either in the same vial or in parallel (5). These results highlight the need for further studies with AIT in polysensitized patients, especially under clinical practice conditions. Such studies will provide results under real-world conditions, as the controlled trials do not represent the actual patient population observed in clinical practice (6).

This is the first preliminary study conducted under routine clinical practice conditions in which the effectiveness of an extract containing a mixture of Dermatophagoides sp. mite allergens and Alternaria sp. mold is evaluated in patients with asthma and/or rhinitis that are polysensitized to HDM and mold.

\section{Methods}

\section{Study design}

Observational, retrospective, and interventional study conducted under routine clinical practice conditions in the Allergology Clinic of La Plana Hospital in Vila-Real (Castellón, Spain), in which the quality of life of patients sensitized to HDM and mold receiving immunotherapy with a mixture of Dermatophagoides sp. mites and Alternaria sp. mold allergens was evaluated. All patients gave verbal informed consent. The study was approved and validated by the Ethics Committee of the hospital, and conducted in accordance with the ethical standards established in the Declaration of Helsinki of 1946.

\section{Study population}

From all the patients treated with specific AIT who attended the specialized Allergology Clinic, we selected those with asthma and/or rhinitis, with clinically relevant sensitization to the HDM Dermatophagoides pteronyssinus and D. farinae, and to the mold Alternaria alternata, and who had also been treated with immunotherapy based on a mixture of allergens of these species (Allergovac Rapid ${ }^{\circledR}$, Roxall, Zamundio, Spain). These patients met the usual criteria for receiving immunotherapy: 1) specific $\mathrm{IgE}$ antibodies to relevant allergens by skin prick test; 2) symptoms clearly related to exposure to the allergen; and 3) persistence of symptoms after adequate implementation of prophylactic environmental control measures.

\section{Study treatment}

Allergovac Rapid ${ }^{\circledR}$ vaccine consists of a sterile suspension of allergenic extracts absorbed in aluminium hydroxide in $0.5 \%$ phenol salt solution and $0.3 \%$ human serum albumin. Some of the main allergens are as follows: Der p $10.88 \mu \mathrm{g} / \mathrm{ml}$, Der p $21.38 \mu \mathrm{g} /$ $\mathrm{ml}$, Der f $10.68 \mu \mathrm{g} / \mathrm{ml}$, Der f $20.89 \mu \mathrm{g} / \mathrm{ml}$ and Alt a $10.07 \mu \mathrm{g} /$ $\mathrm{ml}$. The vaccine is presented in two vials with increasing concentrations that are administered subcutaneously in alternate arms every week for the first 4 weeks, and then every 4 weeks.
After completion of all doses of Allergovac Rapid ${ }^{\circledR}$ vaccine, maintenance was performed with a sterile suspension of an extract of $D$. pteronyssinus, D. farinae, and A. alternata (Allergovac Depot $^{\circledR}$, Roxall, Zamundio, Spain). This vaccine contains the same concentrations of allergens as the starting vaccine and is administered every 4 weeks.

\section{Outcome measures}

Several questionnaires were completed at the time of the vaccine administration, at 6 and 12 months later: Patients with asthma used the Asthma Control Test (ACT) and the Asthma Quality of Life Questionnaire (AQLQ), and patients with rhinitis completed the ESPRINT-15 questionnaire, which evaluated the control of the disease and the quality of life of patients. All questionnaires were validated for the Spanish population (7-9). The ACT questionnaire is used to assess the degree of asthma control in a simpler way than other questionnaires, such as the Asthma Control Diary (ACD) (10) or the Asthma Control Questionnaire (ACQ) (11). In addition, this questionnaire can provide the physician with information on the patients' perception of the degree of control of their disease. The main advantage of ACT is that allows to assess asthma control without pulmonary function values. It consists of 5 items covering 5 dimensions: difficulty in breathing, use of emergency medication, impact of asthma on daily activities, nighttime awakening, and perception of asthma control. Each item is scored from 1 to 5 , so that the overall score ranges from 5 (worst possible asthma control) to 25 (optimal control) (9).

The AQLQ test measures the quality of life of patients with asthma by evaluating both the physical and emotional impact of the disease. It consists of 32 items grouped into 5 dimensions: symptoms (11 items), emotional function (5 items), environmental exposure ( 4 items), and activity limitation (12 items, of which 5 refer to daily activities that the patient can choose from a list of 26 possibilities). The responses for each item range from 1 (severely affected) to 7 (unaffected) (7).

The ESPRINT-15 questionnaire consists of 15 items distributed in 5 dimensions: symptoms ( 5 items), daily activities (3 items), sleep ( 3 items), psychological impact ( 3 items), and general health ( 1 item). The score obtained, either globally or for each dimension, ranges from 0 (no impact on quality of life) to 6 points (maximum impact on quality of life) (8).

\section{Statistical analysis}

The primary endpoint was the absolute and relative change in the mean ACT, AQLQ, and ESPRINT-15 scores from the time of vaccine administration to 6 and 12 months. The Wilcoxon non-parametric test was used to evaluate the ACT scale.

The sample size was estimated considering an alpha error of 0.05 and a beta error of 0.20 and therefore a power of $80 \%$. 
Assuming a $50 \%$ reduction in the mean score of the questionnaires, it was estimated that 24 patients were needed.

The qualitative variables will be analyzed with their frequency distribution and their association by means of the Chi-square test. Quantitative variables were expressed as means and standard deviation (SD) in the case of following a Gaussian curve distribution, or as medians and interquartile ranges in the case of asymmetry. The $95 \%$ confidence intervals $(95 \%$ CI) of the effects obtained were calculated when necessary and their statistical significance by Student's t test for paired data. An ANCOVA analysis was performed to adjust for confounding factors. The analysis of the data was done using the program STATA ver. 12.0.

\section{Results}

\section{Patient characteristics}

A total of 39 patients with a mean age of 21.19 years were included; $48.7 \%$ suffered from rhinitis and the other $48.7 \%$ from rhinitis and asthma. Only $2.6 \%$ suffered only from asthma. Sixty-four per cent presented co-sensitization (table I). Some of these sensitizations were to olive tree pollen ( 3 cases, $7.7 \%$ ), grasses ( 2 cases, $5.1 \%$ ), or a combination of olive tree and Parietaria sp. pollen (2 cases, 5.1\%). Each of the other patients showed different sensitization to a combination of various antigens.

\section{Asthma Control Test results}

There was a statistically significant improvement in asthma control according to the ACT from the administration of the vaccine to 6 and 12 months ( $p=0.007$ and $p=0.042$, respectively)

Table I - Patients' characteristics $(n=39)$.

\begin{tabular}{lcc}
\cline { 2 - 2 } Age, mean $( \pm$ SD) & N & \% \\
Sex & $21.19(13.28)$ & \\
$\quad$ Female & 19 & 48.7 \\
$\quad$ Male & 20 & 51.3 \\
Diagnosis & & \\
$\quad$ Rhinitis & 19 & 48.7 \\
$\quad$ Rhinitis + asthma & 19 & 48.7 \\
$\quad$ Asthma & 1 & 2.6 \\
Previous sensitizations & & \\
$\quad$ No & 14 & 35.9 \\
$\quad$ Yes & 25 & 64.1 \\
\hline
\end{tabular}

SD: standard deviation. (table II). At baseline, the score was 18.24 (partially controlled asthma), and at 6 and 12 months, 21.39 and 22.0 points were reached respectively (well controlled asthma). Of the 18 patients assessed at 6 months, 12 patients (66.7\%) improved their score, $3(16.7 \%)$ maintained the same score, and 3 (16.7\%) worsened. Of the 21 patients assessed at 12 months, 11 (55.0\%) improved, $3(15.0 \%)$ maintained, and $6(30.0 \%)$ got worse.

\section{Asthma Quality of Life Questionnaire results}

According to the AQLQ questionnaire, asthma-related quality of life did not vary significantly between the start of treat-

Table II - Asthma Control Test results.

\begin{tabular}{lcccc}
\cline { 3 - 4 } & \multirow{2}{*}{$\mathbf{N}$} & \multicolumn{2}{c}{ ACT score } & p-value \\
\cline { 3 - 4 } & & Mean & SD & \\
\hline Basal & 21 & 18.24 & 1.165 & Reference \\
6 months & 18 & 21.39 & 0.572 & 0.007 \\
12 months & 21 & 22.00 & 0.793 & 0.042 \\
\hline
\end{tabular}

ACT: Asthma Control Test; SD: standard deviation.

ment and 6 or 12 months after, both globally and in each of the dimensions assessed: chest heaviness, emotions, concerns, and social (table III). According to the global score, of the 17 patients evaluated at 6 months, $11(64.7 \%)$ improved, 1 (5.9\%) maintained the same score, and 5 (29.4\%) got worse. Of the 19 patients assessed at 12 months, $11(57.9 \%)$ improved, 1 (5.3\%) maintained, and 7 (36.8\%) got worse.

\section{Rhinitis control and quality of life for patients with rhinitis}

According to the ESPRINT-15 questionnaire, the 39 patients evaluated described a significant improvement in quality of life at both 6 and 12 months after starting the administration of the vaccine (table IV). This improvement was observed both in the overall score and in each of the 5 dimensions evaluated. Of the 35 patients assessed at 6 months, $27(77.1 \%)$ improved their score, $1(2.9 \%)$ obtained the same score as at baseline, and 7 (20.0\%) worsened. Of the 39 patients assessed at 12 months, 30 (76.9\%) improved their score, $3(7.7 \%)$ maintained the same score, and 6 (15.4\%) got worse. According to item 15, referring to how patients describe their health considering only rhinitis, $79.5 \%$ said it was excellent, very good, or good at the beginning of treatment, $82.1 \%$ at 6 months, and $89.7 \%$ at 12 months. Both at the beginning and at 6 months, only one patient con- 
Table III - Asthma Quality of Life questionnaire.

\begin{tabular}{cccc} 
& \multicolumn{3}{c}{$\begin{array}{c}\text { AQLQ score } \\
\text { Mean }(\mathbf{S D}) \text { and } \mathbf{p} \text {-value }\end{array}$} \\
\cline { 2 - 4 } & $\begin{array}{c}\text { Basal } \\
(\mathbf{N}=\mathbf{2 0})\end{array}$ & $\begin{array}{c}\mathbf{6} \text { months } \\
(\mathbf{N}=\mathbf{1 7})\end{array}$ & $\begin{array}{c}\mathbf{1 2} \text { months } \\
(\mathbf{N}=\mathbf{1 9})\end{array}$ \\
\hline Overall & $2.12(0.38)$ & $1.52(0.39)$ & $1.43(0.38)$ \\
& & $\mathrm{p}=0.179$ & 0.157 \\
\hline Chest heaviness & $2.00(0.38)$ & $1.62(0.45)$ & $1.67(0.44)$ \\
& & $\mathrm{p}=0.379$ & $\mathrm{p}=0.509$ \\
\hline Emotions & $2.30(0.53)$ & $1.79(0.46)$ & $1.50(0.44)$ \\
& & $\mathrm{p}=0.293$ & 0.255 \\
\hline Concerns & $1.71(0.38)$ & $1.34(0.39)$ & $1.29(0.36)$ \\
& & $\mathrm{p}=0.280$ & 0.517 \\
\hline Social & $1.70(0.45)$ & $1.28(0.46)$ & $1.26(0.39)$ \\
& & $\mathrm{p}=0.138$ & $\mathrm{p}=0.527$ \\
\hline
\end{tabular}

AQLQ: Asthma Quality of Life Questionnaire; SD: standard deviation.

sidered his health to be poor. However, at 12 months no patient considered their health to be poor.

\section{Discussion}

This is the first study that evaluates data collected on the use of immunotherapy based on a combination of HDM and mold allergens in patients sensitized with asthma and/or rhinitis in routine clinical practice. The results gathered in this study have shown that this allergen-mixed vaccine significantly improves asthma and rhinitis control and the quality of life of patients. Until now, it was assumed that this type of mixture was not functional because the enzymatic activity of some allergens compromised the structural integrity of others (12-17). However, a study by Grier et al. showed that immunotherapy based on a combination of allergens from different species is possible (18). Their hypothesis was based on the ability of glycerin to inhibit the proteolytic activity of allergens in the extracts. Using variable concentrations of glycerin, mixtures were prepared with allergens from HDM, molds, plants, and animals from different sources. The study showed that some of the mixtures considered as unstable, had a considerable biochemical compatibility, which opened the possibility of developing new formulations, doses, and treatments for patients (18). In fact, in our study we were able to verify that a mixture of allergens from mites and mold is effective.

Studies conducted so far have evaluated the efficacy of subcutaneous immunotherapy based on mite extract and that based on fungal extract separately (19-22). One of these studies assessed the subcutaneous administration of different doses of long-acting $D$. pteronyssinus extracts to patients with allergic rhinocon- junctivitis (19). Compared with placebo, subcutaneous administration of an extract of these mites reduced sensitization to allergens, increasing IgG levels and decreasing IgE levels. In addition, this effect increased with the dose of the extract (19). Another study assessed the safety and tolerability of subcutaneous administration of a long-acting $D$. pteronyssinus extract to patients with allergic rhinoconjunctivitis with or without asthma who are sensitized to this mite (20). The results of the study showed a good safety and tolerability profile of the extract, providing a significant increase in IgG and IgG4 compared with placebo (20).

Other studies did the same with extracts from mold. In one of them, the effect of an extract of $A$. alternata was analyzed in patients with rhinitis and/or bronchial asthma sensitized to this mold (21). A decrease in conjunctival reactivity was observed in a provocation test, although there was no change in the skin reactivity of the prick test. A decrease in $\mathrm{IgE}$ levels and an increase in $\operatorname{IgG}, \operatorname{IgG1}$, and IgG4 levels were also observed (21). Another study evaluated the safety and efficacy profile of $A$. alternata extract in patients with rhinitis and/or bronchial asthma who are sensitized to the mold (22). Six months after administration of the extract, a significant improvement in respiratory symptoms compared to placebo was observed, decreasing both the severity of asthma and rhinitis (22).

In the latter study, the evaluation of the quality of life of patients using the AQLQ questionnaire is also relevant (22). Although treatment improved the quality of life of both asthma and rhinitis patients compared to placebo, the difference was not statistically significant. A significant improvement was only observed in the symptom dimension in patients with asthma, and in the 
Table IV - ESPRINT-15 questionnaire.

\begin{tabular}{|c|c|c|c|}
\hline & \multirow{2}{*}{\multicolumn{3}{|c|}{$\begin{array}{c}\text { ESPRINT-15 score } \\
\text { Mean (SD) and p-value }\end{array}$}} \\
\hline & & & \\
\hline & $\begin{array}{c}\text { Basal } \\
(N=39)\end{array}$ & $\begin{array}{c}6 \text { months } \\
(\mathrm{N}=35)\end{array}$ & $\begin{array}{l}12 \text { months } \\
(\mathrm{N}=39)\end{array}$ \\
\hline Overall & $2.38(0.23)$ & $\begin{array}{c}1.63(0.24) \\
p=0.001\end{array}$ & $\begin{array}{c}1.45(0.18) \\
\mathrm{p}<0.001\end{array}$ \\
\hline Symptoms & $2.96(0.25)$ & $\begin{array}{c}2.06(0.23) \\
\mathrm{p}=0.001\end{array}$ & $\begin{array}{c}1.91(0.21) \\
\mathrm{p}<0.001\end{array}$ \\
\hline Daily activities & $1.92(0.26)$ & $\begin{array}{l}1.18(0.23) \\
\mathrm{p}=0.005\end{array}$ & $\begin{array}{c}1.08(0.19) \\
\mathrm{p}=0.004\end{array}$ \\
\hline Sleeping & $2.16(0.26)$ & $\begin{array}{c}1.67(0.29) \\
\mathrm{p}=0.064\end{array}$ & $\begin{array}{l}1.29(0.24) \\
\mathrm{p}=0.001\end{array}$ \\
\hline Psychological affectation & $1.92(0.28)$ & $\begin{array}{l}1.41(0.28) \\
\mathrm{p}=0.023\end{array}$ & $\begin{array}{c}0.96(0.20) \\
\mathrm{p}=0.002\end{array}$ \\
\hline
\end{tabular}

*"In general, considering your rhinitis and no other disorder, how would you describe your health?"; SD: standard deviation.

emotional state dimension in patients with rhinitis (22). In our study, we observed an improvement in all dimensions of the questionnaire, but none were statistically significant with respect to baseline, probably due to short duration of AIT at that moment. According to the study that established reference values for the ESPRINT-15 questionnaire based on the severity of allergic rhinitis, the mean scores for patients with moderate to severe persistent rhinitis were 2.6 (SD 1.2) in men and 2.7 (SD 1.3) in women (23). In our study, the baseline score was 2.38 (SD 0.23 ), which would classify patients as having moderate to severe persistent rhinitis. The administration of the combination vaccine allowed a statistically significant reduction in this value to 1.63 (SD 0.24) 6 months later $(\mathrm{p}=0.001)$, and to 1.45 (SD $0.18) 12$ months after starting treatment $(\mathrm{p}<0.001)$.

The main limitation of this study is the common one in retrospective studies conducted in clinical practice, especially regarding the establishment of a control group. For this reason, the results do not necessarily have to be universally valid or be extrapolated to other groups of patients, although they do open the way to further studies to corroborate and extend the results obtained in this one.

\section{Conclusions}

The results of our preliminary study show that the administration of specific immunotherapy based on the combination of allergens from the mites $D$. pteronyssinus and $D$. farinae, and the mold $A$. alternata, seems to be effective and possibly able to increase the quality of life of patients with asthma and/or rhinitis. This outcome needs to be confirmed by randomized placebo-controlled trials.

\section{Fundings}

Roxal has sponsored this project without participating in any way in the design, data analysis or writing of this article.

\section{Acknowledgements}

The authors wish to thank Fernando Sánchez Barbero PhD. for the support on the preparation of this manuscript.

\section{Conflict of interests}

The authors declare that they have no conflict of interests.

\section{References}

1. Focke M, Swoboda I, Marth K, Valenta R. Developments in allergen-specific immunotherapy: from allergen extracts to allergy vaccines bypassing allergen-specific immunoglobulin $\mathrm{E}$ and $\mathrm{T}$ cell reactivity. Clin Exp Allergy 2010;40(3):385-97.

2. Incorvaia C. Preventive capacity of allergen immunotherapy on the natural history of allergy. J Prev Med Hyg 2013;54(2):71-4.

3. European Medicines Agency. Guideline on allergen products: production and quality issues. London; 2008 EMEA/CHMP/ BWP/304831/2007. Available at: https://www.ema.europa.eu/ en/allergen-products-production-quality-issues. Last access date: 05/01/2020. 
4. Demoly P, Passalacqua G, Pfaar O, Sastre J, Wahn U. Management of the polyallergic patient with allergy immunotherapy: a practice-based approach. Allergy Asthma Clin Immunol 2016;12:2.

5. Wahn U, Calderon MA, Demoly P. Real-life clinical practice and management of polysensitized patients with respiratory allergies: a large, global survey of clinicians prescribing allergen immunotherapy. Expert Rev Clin Immunol 2017;13(3):283-9.

6. Incorvaia C, Barberi S, Pastorello E, Ciprandi G. The growing importance of real-life studies in allergen immunotherapy. Eur Ann Allergy Clin Immunol 2019;51(3):115-21.

7. Sanjuàs C, Alonso J, Sanchís J, et al. [The quality-of-life questionnaire with asthma patients: the Spanish version of the Asthma Quality of Life Questionnaire]. Arch Bronconeumol 1995;31(5):219-26.

8. Valero A, Baró E, Sastre J, et al. Reference values for facilitating the interpretation of the ESPRINT-15 questionnaire (Spanish version). J Investig Allergol Clin Immunol 2009;19(5):396-403.

9. Vega JM, Badia X, Badiola C, et al. Validation of the Spanish version of the Asthma Control Test (ACT). J Asthma 2007;44(10):867-72.

10. Juniper EF, O'Byrne PM, Ferrie PJ, King DR, Roberts JN. Measuring asthma control. Clinic questionnaire or daily diary? Am J Respir Crit Care Med 2000;162(4 Pt 1):1330-4.

11. Juniper EF, O'Byrne PM, Guyatt GH, Ferrie PJ, King DR. Development and validation of a questionnaire to measure asthma control. Eur Respir J 1999;14(4):902-7.

12. Wongtim S, Lehrer SB, Salvaggio JE, Horner WE. Protease activity in cockroach and basidiomycete allergen extracts. Allergy Proc 1993;14(4):263-8.

13. Esch RE. Role of proteases on the stability of allergenic extracts. Arb Paul Ehrlich Inst Bundesamt Sera Impfstoffe Frankf A M 1992(85):171-7; discussion 7-9.

14. Meier EA, Whisman BA, Rathkopf MM. Effect of imported fire ant extract on the degradation of mountain cedar pollen allergen. Ann Allergy Asthma Immunol 2006;96(1):30-2.
15. Hoff M, Krail M, Kastner M, Haustein D, Vieths S. Fusarium culmorum causes strong degradation of pollen allergens in extract mixtures. J Allergy Clin Immunol 2002;109(1):96-101.

16. Nelson HS, Ikle D, Buchmeier A. Studies of allergen extract stability: the effects of dilution and mixing. J Allergy Clin Immunol 1996;98(2):382-8

17. Kordash TR, Amend MJ, Williamson SL, Jones JK, Plunkett GA. Effect of mixing allergenic extracts containing Helminthosporium, D. farinae, and cockroach with perennial ryegrass. Ann Allergy 1993;71(3):240-6.

18. Grier TJ, LeFevre DM, Duncan EA, Esch RE. Stability of standardized grass, dust mite, cat, and short ragweed allergens after mixing with mold or cockroach extracts. Ann Allergy Asthma Immunol 2007;99(2):151-60.

19. Moreno V, Alvariño M, Rodríguez F, et al. Randomized dose-response study of subcutaneous immunotherapy with a Dermatophagoides pteronyssinus extract in patients with respiratory allergy. Immunotherapy 2016;8(3):265-77.

20. Hernández Fernández de Rojas D, Antépara Ercoreca I, Ponte Tellechea A, et al. Phase I study of subcutaneous allergen immunotherapy with Dermatophagoides pteronyssinus in patients with allergic rhinoconjunctivitis with or without asthma. Immunotherapy 2015;7(2):89-99.

21. Lizaso MT, Tabar AI, García BE, et al. Double-blind, placebo-controlled Alternaria alternata immunotherapy: in vivo and in vitro parameters. Pediatr Allergy Immunol 2008;19(1):76-81.

22. Tabar AI, Lizaso MT, García BE, et al. Double-blind, placebo-controlled study of Alternaria alternata immunotherapy: clinical efficacy and safety. Pediatr Allergy Immunol 2008;19(1):67-75.

23. Valero A, Izquierdo I, Sastre J, et al. ESPRINT-15 questionnaire (Spanish version): reference values according to disease severity using both the original and the modified ARIA classifications. J Investig Allergol Clin Immunol 2013;23(1):14-9. 